\title{
Immunological Responses in Pregnancy and Survival of Fetal Homograft
}

\author{
RONALD FINN, \\ VIVIEN DENYE \\ C. A. ST. HILL, A. JANE GOVAN, I. G. RALFS, FRANCES J. GURNEY,
}

British Medical fournal, 1972, 3, 150-152

\begin{abstract}
Summary
Immunological responses were studied in pregnant women and controls using as tests phytohaemagglutinin-induced lymphocyte transformation and the tuberculin reaction. Significantly reduced responses were found to both tests in the pregnant women. These results suggest that a reduction in $\mathbf{T}$-cell activity during pregnancy may help protect the fetus from rejection by its mother's immunological mechanisms.
\end{abstract}

\section{Introduction}

The possible existence of a state of immunological inertia associated with viviparity has attracted much attention (Anderson, 1971), and we first became interested in this subject in relation to studies on the prevention of $\mathrm{Rh}$-haemolytic disease (Finn, 1970; Clarke and McConnell, 1972). Small numbers of fetal red cells enter the maternal circulation during pregnancy but primary $\mathrm{Rh}$ sensitization does not usually occur until after delivery, suggesting that the maternal immunological response to fetal products may be depressed during pregnancy.

The fetus, by virtue of its paternal complement of genes, must carry histocompatibility antigens foreign to the mother and should be rejected. The protection of the fetus has been attributed to the placental barrier, and this undoubtedly plays an important part (Woodruff, 1957). Consideration of the pathogenesis of Rh-haemolytic disease, however, casts serious doubts on the completeness of the immunological barrier function of the placenta. It has been shown that fetal red cells and white cells carrying immunological information cross the placenta into the maternal circulation, and that $\mathrm{Rh}$ antibody (IgG) crosses back into the fetus. It is thus evident that the placenta does not constitute a total immunological barrier, and the survival of the fetus may also depend on complex immunological adjustments between mother and fetus. We therefore decided to study cell-mediated immunity in pregnancy using phytohaemagglutinin-induced lymphocyte transformation and the tuberculin reaction as tests of cellular immunity.

\section{Material and Methods}

Lymphocytes from pregnant women and control subjects were stimulated with phytohaemagglutinin by means of a standard technique. A $0 \cdot 4-\mathrm{ml}$ blood sample collected in pre-

\footnotetext{
Nuffield Unit of Medical Genetics, Department of Medicine, University of Liverpool

RONALD FINN, M.D., F.R.C.P., Consultant Physician

Royal Southern Hospital, Liverpool 8

C. A. ST. HILL, M.B., F.R.C.PATH., Consultant Pathologist

FRANCES J. GURNEY, A.I.M.L.T., Technician

VIVIEN DENYE, A.I.M.L.T., Technician

Renal Unit, Sefton General Hospital, Liverpool 15

A. JANE GOVAN, M.B., D.oBST.R.C.o.G., Senior House Officer

I. G. RALFS, M.B., CH.B., Senior House Officer
}

servative-free heparin in plastic bottles was added to $4.5 \mathrm{ml}$ of culture medium. This consisted of $10 \mathrm{ml}$ of medium TC 199 (Wellcome, tenfold concentrated), $5 \mathrm{ml}$ of sterile $4.4 \%$ sodium bicarbonate, 20,000 units of penicillin, $20 \mathrm{mg}$ of streptomycin, and $85 \mathrm{ml}$ of sterile distilled water. To this mixture $1.5 \mathrm{ml}$ of autologous plasma and $0.05 \mathrm{ml}$ of phytohaemagglutinin (Wellcome) were added. After incubation for 69 hours at $37^{\circ} \mathrm{C} 0.6 \mathrm{ml}$ of $0.02 \%$ solution of colchicine in saline was added and the incubation continued for a further three hours. The tubes were then centrifuged at 500 r.p.m. for five minutes, the supernatant fluid was discarded, and the cells were made to swell by the addition of $4 \mathrm{ml}$ of 0.075 molar potassium chloride for three minutes at $37^{\circ} \mathrm{C}$. At the end of this time the tubes were recentrifuged, the cells fixed in a 3:1 methanol-glacial acetic acid mixture with shaking, and films were made on grease-free slides. These were stained with a Leishman-Giemsa mixture and viewed at a magnification of 500 with a fluorite $\times 50$ oil immersion lens.

The transformation rate was assessed morphologically by two methods. The first depended on the size and density of the nucleus, a transformed cell being defined as one in which the nucleus was at least doubled in size and the nuclear staining much reduced, with or without nucleoli. In the second method only cells containing well-defined nucleoli were accepted as being transformed, irrespective of their size. The first method was found to be less sensitive and the transformation rate was calculated after a count of 1,000 cells; the second method, involving the recognition of nucleoli, was more sensitive and only 200 cells were counted.

Each batch of cultures contained blood from pregnant and non-pregnant subjects, and the final slides were coded so that the observer was not aware of the origin of the lymphocytes on a particular slide. The coding was done by another member of the team so that all slides were counted blindly to avoid possible bias. The aim was to compare the transformation rates on phytohaemagglutinin stimulation of lymphocytes from pregnant and control subjects. Although the morphological assessment of transformation is laborious and time-consuming the consistency of the results compares favourably with isotope techniques (Astaldi et al., 1969).

In order to assess further the response of pregnant and nonpregnant lymphocytes to phytohaemagglutinin stimulation varying dilutions of phytohaemagglutinin were used to construct dose-response curves. Again the slides were coded and read blindly to avoid bias.

The response of lymphocytes to phytohaemagglutinin stimulation is a measure of cell-mediated immunity as opposed to humoral immunity. Cell-mediated immunity can also be tested by means of certain intradermal reactions, including the tuberculin test. We accordinagly carried out Mantoux tests on another series of pregnant women and non-pregnant female controls. An injection of $0.1 \mathrm{ml}$ of $1: 1,000$ old tuberculin was given intradermally and the reaction measured at 48 hours. For the purposes of this comparison a negative reaction was defined as one in which there was no trace of induration or flare at 48 hours.

\section{Results}

Phytohaemagglutinin Stimulation.-The lymphocyte transformation rate in 34 pregnant women and 27 non-pregnant 
controls was assessed by using the size and density of the nucleus as an index of transformation (Fig. 1). The mean transformation rate in the controls was $59.8 \%$ and in the pregnant women $48.6 \%(t=3.58,59$ D.F., $\mathrm{P}<0.001)$. With the use of the second criterion of transformation-namely, the identification of nucleoli-16 pregnant women and 13 controls were scored (Fig. 2). The mean transformation rate was $59 \%$ in the controls

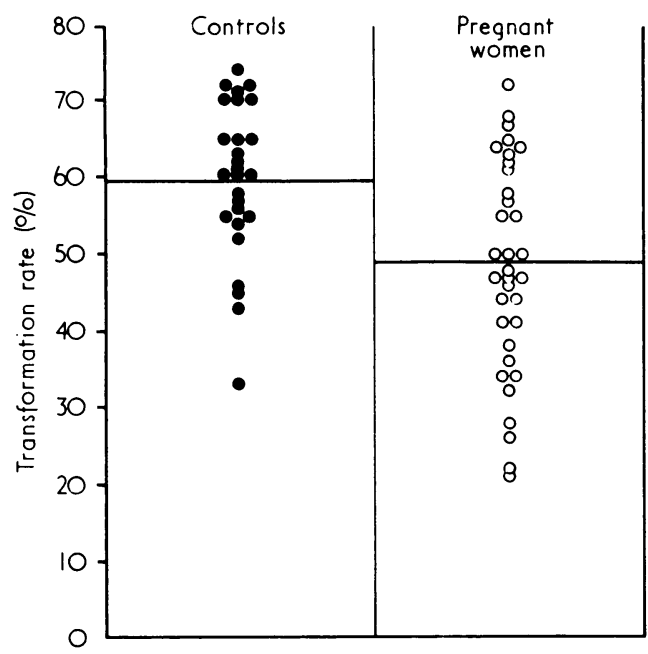

FIG. 1-Phytohaemagglutinin-induced transformation rate in pregnant women and controls. Transformation rate assessed by method 1 (see text).

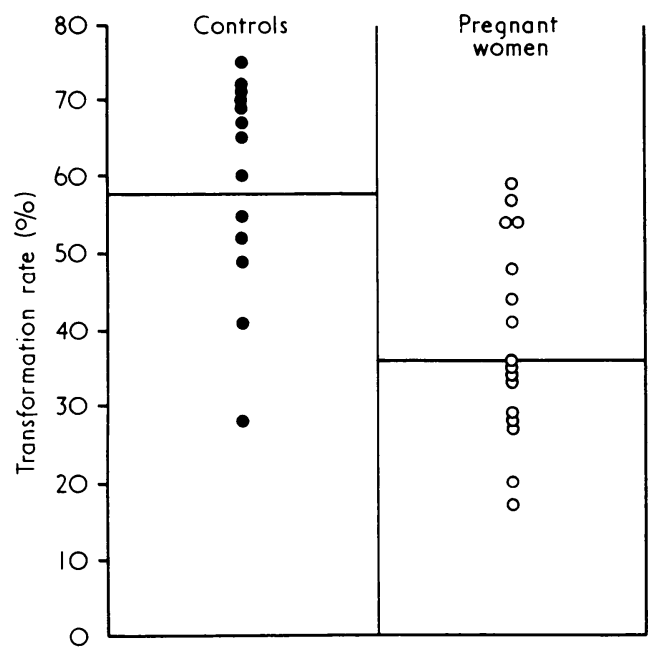

FIG. 2-Phytohaemagglutinin-induced transformation rate in pregnant women and controls. Transformation rate assessed by method 2 (see text).

and $36.6 \%$ in the pregnant women $(t=4.64,27$ D.F., $\mathbf{P}<0.001)$. These results indicate that the phytohaemagglutinininduced transformation rate is reduced in pregnancy. The difference is most evident if the presence of nucleoli is taken as the criterion of transformation rather than nuclear size and density.

Phytohaemagglutinin Dilution Studies.-The transformation rate was assessed with different dilutions of phytohaemagglutinin. The results are shown in Fig. 3, which is based on 181 determinations carried out on 27 pregnant women and 22 controls. The mean transformation rate was calculated at each dilution of phytohaemagglutinin, and dose-response curves were constructed for the pregnant and control subjects. Both sets of observations can be fitted satisfactorily by straight lines on the logarithmic scale for the stimulus. If parallel lines are fitted the distance between them is 1.71 on the logarithmic scale and is highly significantly different from zero $(F=38.4$,
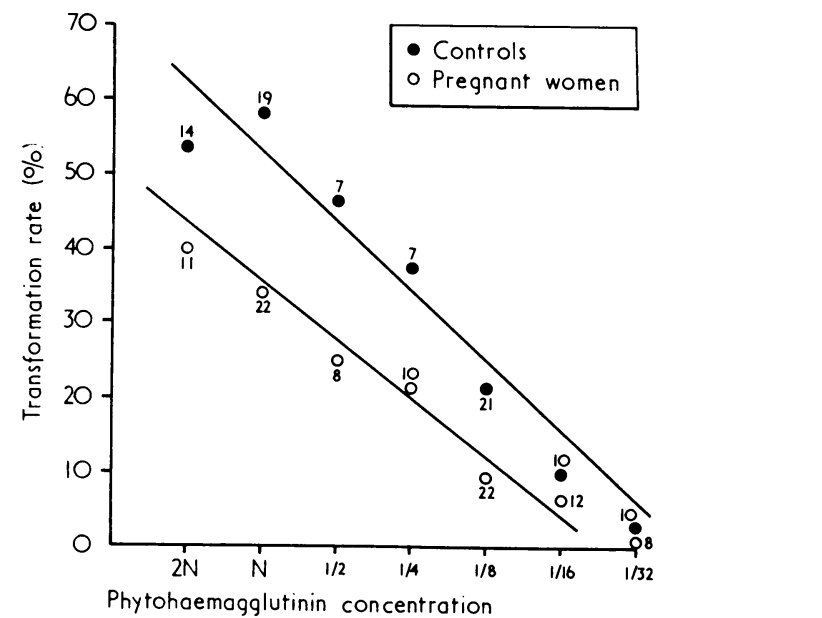

FIG. 3-Dose-response curve of phytohaemagglutinin-induced transformation rate with varying concentrations of phytohaemagglutinin in pregnant women and controls. Number at each point indicates number of observations from which mean transformation rate was calculated. $N$ equivalent to $0.05 \mathrm{ml}$ phytohaemagglutinin.

with 1 and 151 D.F., giving $P<0.005)$. The difference of 1.71 on the logarithmic scale implies that the pregnant women require on average a stimulus about 3.27 times as strong, in absolute units, as that for the control women to produce an equal response. Fitting separate straight lines without forcing them to be parallel-that is, to have equal slopes-does not produce a significantly better fit $(F=3.55$, with 1 and 151 D.F., giving $\mathrm{P}<0.05)$. These results also indicate that phytohaemagglutinin-induced lymphocyte transformation is reduced in pregnancy.

Tuberculin Studies.-Out of 97 control subjects tested 27 $(27.8 \%)$ were completely negative, and of 99 pregnant women tested $43(43.3 \%)$ were negative $\left(\chi^{2}=4.54, \mathrm{P}<0.05\right)$. These results indicate that the tuberculin reaction is depressed in pregnancy.

\section{Discussion}

Phytohaemagglutinin-induced lymphocyte transformation (Doenhoff et al., 1971) and the tuberculin reaction are recognized tests of cell-mediated immunity. These results therefore indicate that there is a reduction in cell-mediated immunity in pregnancy, and this observation is open to two interpretations. It could be an epiphenomenon of pregnancy without any specific meaning or purpose, or it could indicate some meaningful alteration in immunological status associated with pregnancy. The available evidence appears to support the second alternative. The protection of the mother from infection during pregnancy is critical for the survival of the species, and it is difficult to explain how selection pressures occurring in the course of evolution would allow any depression of immunological responses to take place in pregnancy unless there were some compensatory survival value.

The explanation may lie in the protection of the fetal homograft. Immunological information certainly crosses the placental barrier and reaches the mother because specific HL-A antibodies are not uncommon in multiparous women, but although they can cross the placenta they do not seem to harm the fetus. Lanman and Herod (1965) concluded that humoral antibody cannot by itself cause fetal rejection and that the placenta holds back sensitized lymphocytes which would be capable of causing rejection of the fetal homograft. There is, however, a large volume of evidence relating to $\mathrm{Rh}$-haemolytic disease which indicates that transplacental passage of red cells (and therefore of white cells) from fetus to mother occurs in pregnancy (Woodrow and Finn, 1966), and it is hard to conceive that the occasional passage of sensitized lymphocytes does not take 
place in the opposite direction into the fetus, although this has not been conclusively shown (Walknowska et al., 1969; Anderson and Ferguson-Smith, 1971). It is evident that cellular elements and some antibodies cross the placenta, and hence it does not constitute an absolute immunological barrier between mother and fetus. It may be postulated that mechanisms will have evolved for neutralizing the occasional sensitized lymphocyte which gains access to the fetus.

Two systems of lymphocytes are now recognized. The thymus-derived system ( $T$ cells) is responsible for cell-mediated immunity and is mainly responsible for dealing with abnormal cellular elements such as mutant cells, neoplasms, organ grafts, and virus infections. The bursa-derived system of lymphocytes (B cells) is concerned with the production of humoral or free antibody and is primarily concerned with defence against foreign bacteria. If the above analysis is correct and the task in pregnancy is to neutralize the occasional lymphocyte which traverses the placenta, one might predict that B-cell function in pregnancy would not be reduced and might even be increased in order to protect against bacterial infection, but that $\mathrm{T}$-cell activity (cell-mediated immunity) would be restricted. It is therefore significant that Woodrow et al. (1971) found no reduction of humoral antibody production in the pregnant rabbit and even a suggestion that it might be increased, whereas the present data indicate that cell-mediated immunity is significantly reduced in pregnancy. It has been shown by several workers in both man and other species that skin-graft survival between mother and newborn infant is significantly prolonged (Anderson, 1971), and this is also compatible with a reduction of cell-mediated immunity in pregnancy.

If cell-mediated immunity is reduced in pregnancy to protect the fetus it might be thought that the mother would be more susceptible to viral infection, but this may not be the case. Recent work on haemodialysis-associated hepatitis has shown that some individuals may carry the virus for many years without experiencing any hepatic damage. It is therefore clear that the $\mathrm{SH}$ virus is not cytotoxic and that clinical hepatitis occurs only as a result of an immunological attack on the virus (Finn, 1971), and it has been suggested that this is a T-cell function (Dudley et al., 1972). It is possible that this situation can be extrapolated to many virus diseases, and one could put forward the general hypothesis that most viruses are not cytotoxic (otherwise they could never multiply intracellularly) but that disease arises only if the virus alters the cell coat sufficiently to precipitate an excessive $\mathrm{T}$-cell response. If this be accepted than a reduction in cell-mediated immunity in pregnancy would not increase the risk of viral disease and may even ameliorate its severity. Perhaps the occasional rapidly spreading neoplasm or lethal viral infection occurring in pregnancy is the price that has to be paid for a reduction in cell-mediated immunity, but these are rare events.

It is necessary to speculate on the mechanism by which cell-mediated immunity is reduced in pregnancy. If the analysis is limited to phytohaemagglutinin-induced lymphocyte transformation rate as a measure of cell-mediated immunity it is possible that some factor coats the lymphocytes and interferes with the "phytohaemagglutinin receptor site." This could be an antibody, a hormone, or another quite small molecule, and it could be derived from the mother, the fetus, or the placenta. Immunological enhancement has been investigated in tumour immunology, and in this situation blocking antibody binds to cells and prevents sensitized lymphocytes from reaching and destroying them. It has been suggested that blocking antibody could protect the fetus from the destructive effects of sensitized lymphocytes which have penetrated the placenta (Hellström et al., 1969). Alternatively there may be a central suppression of $T$ cells in pregnancy with a proportionate increase in B cells, and our results with phytohaemagglutinin stimulation could be due to the fact that there are fewer $T$ cells to be stimulated. The similarity in shape of the two dose-response curves in Fig. 3 could be interpreted as indicating that the response of lymphocytes to phytohaemagglutinin in pregnancy is not qualitatively different, but that there are simply fewer $\mathrm{T}$ cells to be stimulated.

The survival of the fetal homograft poses a challenge to immunology, and there is now abundant evidence that significant immunological changes occur in pregnancy. It is likely that a better understanding of the immunological relation between mother and fetus will lead to more specific techniques for inducing tolerance to transplanted organs.

We would like to thank Professor C. A. Clarke for his help and advice, Mr. M. C. K. Tweedle for statistical help, Mr. J. E. Doig for technical advice, and the Board of Governors of the United Liverpool Hospitals for a research grant.

ADDENDUM.- Since completing this article we have learnt that Purtilo et al. (1972) have also shown that cell-mediated immunity is reduced in pregnancy.

\section{References}

Anderson, J. M. (1971). Lancet, 2, 1077.

Anderson, J. M., and Ferguson-Smith, M. A. (1971). British Medical Fournal, 2, 166.

Astaldi, G., Burgio, G. R., Krc, J., Genova, R., and Astaldi, A. A. (1969). Lancet, 1, 423 .

Clarke, C. A., and McConnell, R. B. (1972). Prevention of Rh-haemolytic Disease. Springfield, Illinois, Thomas.

Doenhoff, M. J., Davies, A. J. S., Leuchars, E., and Wallis, V. (1971). Proceedings of the Royal Society. Series B. Biological Sciences,

Finn, R. (1970). Modern Trends in Paediatrics, ed. J. Apley, p. 23. London, Butterworths.

Butterworths.
Finn, R. (1971). Postgraduate Medical Fournal, 47, 499.

Finn, R. (1971). Postgraduate Medical Fournal, 47, 499. . Nature, 224, 914

Hellström, K. E., Hellström, I., and Brawn, J. (1969). Nature, 224, 914. 579.

Purtilo, D. T., Hallgren, H. M., and Yunis, E. J. (1972). Lancet, 1. 769.

Walknowska, J., Conte, F. A., and Grumbach, M. M. (1969). Lancet, 1, 1119. Woodrow, J. C., Elson, C. J., and Donohoe, W. T. A. (1971). Nature, 233, 62.

Woodrow, J. C., and Finn, R. (1966). British fournal of Haematology, 12, 297.

Woodruff, M. F. A. (1957). Proceedings of the Royal Society, Series B. Biological Sciences, 148, 68 